\title{
An Experimental Canine Model to Study Left Ventricular Function
}

\author{
Siyamek Neragi Miandoab* and Gus Valahakes
}

\author{
Department of Surgery, St. Vincent's Medical Center, New York Medical College, School of Medicine, Department of \\ Surgery, Cardiac Surgery, Massachusetts General Hospital, Harvard Medical School, USA
}

\begin{abstract}
An increasing number of patients with uni- or bi-ventricular heart failure underscores the importance of heart failure research. An isolation of the left or right ventricle would allow for an evaluation of the contralateral ventricular function, the change in hemodynamics, and the capability of each ventricle to deal with the volume challenge. This experimental canine model was developed at the laboratory of Cardiac Physiology at Massachusetts General Hospital, Harvard Medical School. The model allows an evaluation of left ventricular function with a tight control of the preload and evaluation of the contractility of the myocardium to create pressure and handle the volume overload. The left atrial pressure (LAP), left ventricular end diastolic pressure (LVEDP), left ventricular end-systolic pressure (LVES), and myocardial contractility (DP/DT) can be measured using catheters and micro-ultrasound devices. Using this model, a Frank-Starling Curve can be generated for any given circumstance.
\end{abstract}

This manuscript describes the technical aspect of such a model including; preparation of the canines, cannulation, and measurement of intra-cardiac pressures.

\section{INTRODUCTION}

Despite significant progress in the prevention and treatment of cardiovascular diseases [1], the prevalence of heart failure has been increasing in the United States and worldwide. Nevertheless, many patients who are optimally treated with pharmacotherapy continue to progress from asymptomatic left ventricular dysfunction to symptomatic and end-stage heart failure [2-8].

There has been a need for an easy and adjustable experimental model with and without heart failure to study myocardial and left ventricular function [9]. This model would allow studying of each ventricle's contractility separately.

\section{DESCRIPTION OF THE MODEL}

Canines are appropriate animals for this model; however, other larger animals such as sheep or pigs can be used. In this model we used canines $(n=14)$ to study the left ventricular function and the efficacy of priming with Hemoglobin Based Oxygen Carrying Solution (HBOC-201 Biopure, Cambridge, MA) to preserve the left ventricular contractility; however, this manuscript addresses the technical aspects of the model only.

After intubation and anesthesia with isoflurane 1.5-2.5\%, arterial and venous catheters were inserted for hemodynamic measurements. A left thoracotomy was performed and the pericardium was opened and suspended to form a cradle to support the heart. Micromanometer-tipped catheters were inserted into the left atrium and the left ventricle for pressure measurements. The left carotid artery was cannulated as an arterial access for the cardiopulmonary bypass (CPB)

*Address correspondence to this author at the St. Vincent's Medical Center, Department of Surgery, New York Medical College, School of Medicine, 130 West $12^{\text {th }}$ Street, New York, NY 10011, USA; Tel: 212 604- 8308; Fax: 212-604-3628; E-mail: Sneragi@yahoo.com machine. The right atrium and pulmonary artery were cannulated to control the preload of the left ventricle. The right heart was bypassed and venous blood from the right atrium was diverted to the pulmonary circulation and into the left atrium. Systemic anticoagulation was performed with 200 i.E./kg heparin. Lactated Ringer's solution and HBOC201 were used as priming solution in the control group $(\mathrm{n}=7)$ and study group $(\mathrm{n}=7)$, respectively.

After reaching a steady state, hemodynamic parameters were measured. Pre-ischemic left ventricular function curves were generated by controlling the preload via the pulmonary artery. A starting preload of $500 \mathrm{ml}$ was used and the preload was increased by $500 \mathrm{ml} / \mathrm{min}$ in a stepwise fashion to a maximum of $3500 \mathrm{ml}$. After the pre-ischemic measurements, cardiac output was adjusted to $1.75-2.25 \mathrm{~L} / \mathrm{min} \quad(75$ $\mathrm{ml} / \mathrm{min} / \mathrm{kg}$ ) via carotid artery cannulation. The total cardiopulmonary bypass was initiated, the aorta was crossclamped, and systemic cooling to $22-23 \mathrm{C}$ was conducted. The aorta was clamped and crystalloid potassium cardioplegia was infused into the aortic root $(20 \mathrm{ml} / \mathrm{kg})$. The cardioplegia was repeated $30 \mathrm{~min}$ later $(10 \mathrm{ml} / \mathrm{kg})$. Perfusion at $22{ }^{\circ} \mathrm{C}$ was maintained for 60 minutes at a flow rate of 75 $\mathrm{ml} / \mathrm{min} / \mathrm{kg}$. After 60 minutes of ischemic time, the aortic clamp was removed. The heart was electrically converted if spontaneous rhythm did not resume. After 40-50 minutes of rewarming and recovery, the left ventricle function was studied again. Fig. (1) demonstrates the technical design of such a right heart bypass on a canine.

The left atrial pressure (LAP), left ventricular end systolic pressure (LVESP), and left ventricular end diastolic pressure (LVEDP) can be measured pre- and post-ischemia. The cardiac contractility can be measured via microultrasounds placed in the myocardium measuring the contractility as acceleration of the myocardium over time. These data were translated into numbers as an expression of 


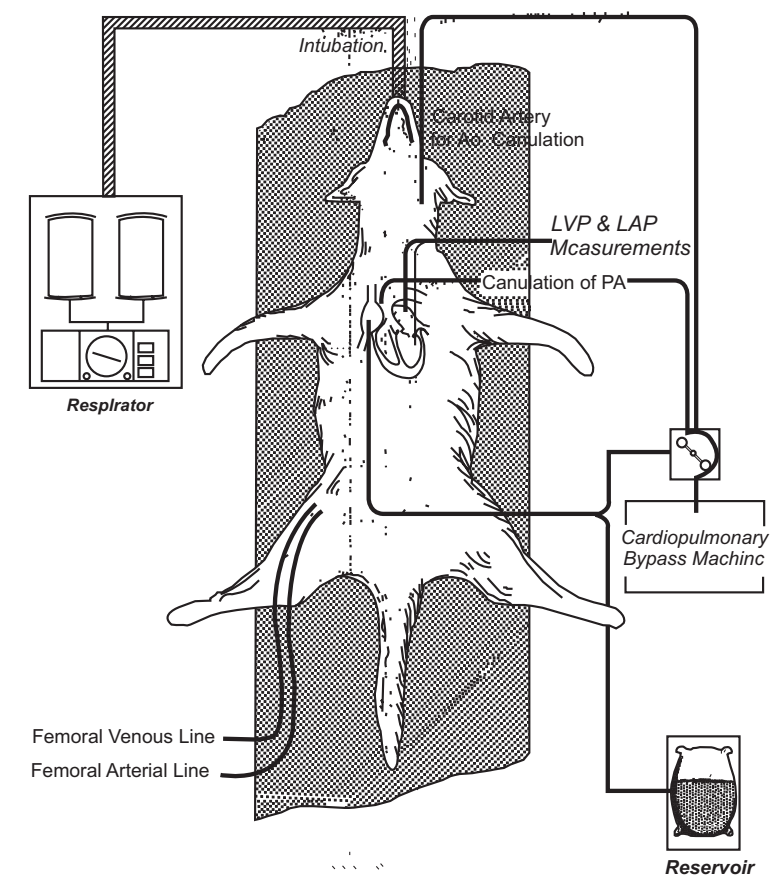

Fig. (1). Illustration of cannulation/cardiopulmonary bypass in our model. Right atrium served for venous cannulation, left carotid for arterial cannulation. Catheters were inserted into left atrium and ventricle. Right femoral artery was cannulated for monitoring of arterial pressure. Right femoral vein was cannulated for blood draws.

change in pressure in myocardium $(\mathrm{mmHg} / \mathrm{ms})$ at any given time. These data were correlated with increasing preload and cardiac output. Fig. (2) demonstrates the Frank-Starling Curves for both control and study group. Table 1 demonstrates the hemodynamic data collected using the right heart bypass in this model. The hemodynamic parameters and myocardial contractility were measured for each given preload. This model is adequate for acute studies and the canines were sacrificed following completion of the study.

\section{COMMENT}

This manuscript describes an easily reproducible animal model to isolate and study the function of the left ventricular. Using this model, the cardiac contractility, intracardiac pressures changes, ability of the myocardium to handle the increasing preload, and the impact of pharmacologic agents can be studied. It also allows Frank-Starling Curves to be generated under various circumstances.

Tamesue et al. [7] proposed a right heart bypass to evaluate the hemodynamic effects of a pumpless, implantable extracorporeal membrane oxygenation (ECMO) circuit between the right ventricle (RV) and left atrium (LA) in a chronic canine model with a RV pressure overload [7]. Melchior et al. [8] introduced rapid, quantified measurements of cardiac output $(\mathrm{CO})$ following weaning from cardiopulmonary bypass (CPB). This novel technology has specific application in open heart surgery [9]. Breen et al. [10] developed a model to study the gas exchange in a canine model, in which cardiac output was controlled and measured. However, none of those models allow for an isolation of the left ventricle to study its function.

Nawa et al. [11] introduced a new experimental model for the total exclusion of the right heart in Mongrel dogs without using a cardiopulmonary bypass. A Y-shaped conduit was introduced into the superior and inferior venae cavae and the pulmonary artery. Thus, the right heart was bypassed and venous blood from the venae cavae was

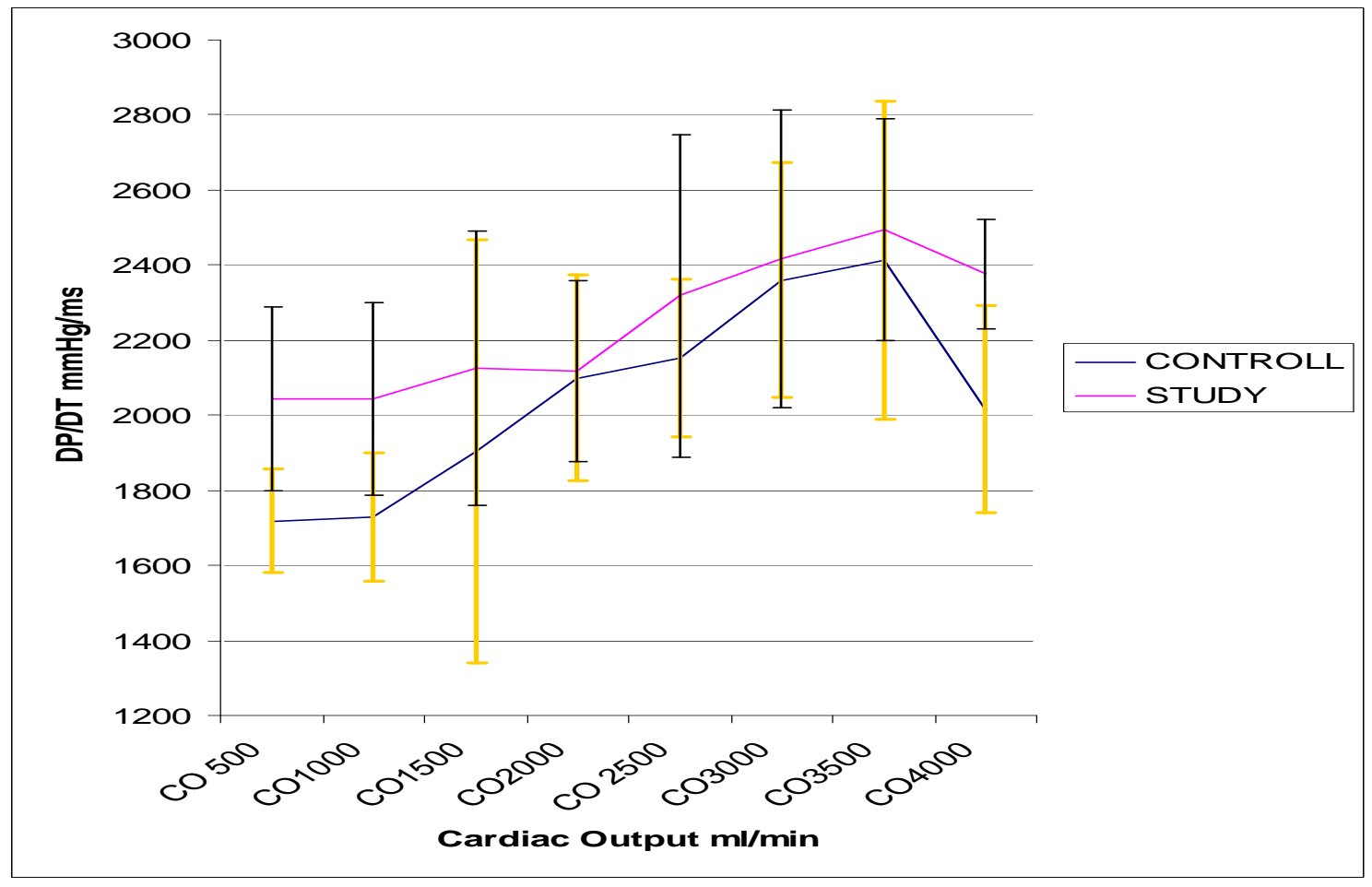

Fig. (2). Frank-Starling Curves for the canines in control $(n=7)$ and study $(n=7)$ group. 
Table 1. Hemodynamic Data Pre- and Post Ischemic

\begin{tabular}{|c|c|c|}
\hline & Pre-Ischemic & Post-Ischemic \\
\hline \multicolumn{3}{|l|}{ CO $500 \mathrm{ml}$} \\
\hline Art pressure & $86 \pm 5$ & $83 \pm 2.9$ \\
\hline LVP & $89 \pm 5.4$ & $85 \pm 7$ \\
\hline $\mathrm{DP} / \mathrm{DT} \mathrm{mmHg} / \mathrm{ms}$ & $1718 \pm 157$ & $1495 \pm 463$ \\
\hline LVEDP & $6.3 \pm 1.7$ & $12 \pm 4.6$ \\
\hline LAP & $5.9 \pm 1.8$ & $10 \pm 3.8$ \\
\hline \multicolumn{3}{|l|}{ CO $1000 \mathrm{ml}$} \\
\hline Art Pressure mmHg & $87 \pm 6$ & $84 \pm 6$ \\
\hline LVP mmHg & $90 \pm 6$ & $90 \pm 8$ \\
\hline $\mathrm{DP} / \mathrm{DT} \mathrm{mmHg} / \mathrm{ms}$ & $1903 \pm 170$ & $1587 \pm 437$ \\
\hline LVEDP (mmHg) & $6 \pm 1.7$ & $14.6 \pm 11$ \\
\hline LAP (mmHg) & $6 \pm 2$ & $11.3 \pm 6$ \\
\hline \multicolumn{3}{|l|}{ CO $1500 \mathrm{ml}$} \\
\hline Art pressure $(\mathrm{mmHg})$ & $89 \pm 7$ & $88 \pm 9$ \\
\hline LVP (mmHg) & $90 \pm 9.5$ & $91 \pm 8.5$ \\
\hline $\mathrm{DP} / \mathrm{DT} \mathrm{mmHg} / \mathrm{ms}$ & $1996 \pm 250$ & $1727 \pm 565$ \\
\hline LVEDP (mmHg) & $7.9 \pm 1$ & $15 \pm 5.9$ \\
\hline LAP(mmHg) & $6.9 \pm 1.6$ & $13 \pm 5.6$ \\
\hline \multicolumn{3}{|l|}{ CO $2000 \mathrm{ml}$} \\
\hline Art pressure (mmHg) & $88 \pm 6$ & $86 \pm 8.9$ \\
\hline LVP(mmHg) & $88 \pm 7.6$ & $91 \pm 9$ \\
\hline $\mathrm{DP} / \mathrm{DT} \mathrm{mmHg} / \mathrm{ms}$ & $2098 \pm 275$ & $1671 \pm 607$ \\
\hline LVEDP (mmHg) & $8.9 \pm 0.9$ & $22 \pm 13$ \\
\hline LAP (mmHg) & $8 \pm 1.7$ & $18 \pm 8.3$ \\
\hline \multicolumn{3}{|l|}{ CO $2500 \mathrm{ml}$} \\
\hline Art pressure $(\mathrm{mmHg})$ & $89 \pm 7.3$ & $87 \pm 5.7$ \\
\hline LVP (mmHg) & $93 \pm 8.5$ & $91 \pm 4$ \\
\hline $\mathrm{DP} / \mathrm{DT}(\mathrm{mmHg} / \mathrm{ms})$ & $2154 \pm 210$ & $1872 \pm 580$ \\
\hline LVEDP (mmHg) & $9.9 \pm 3$ & $22 \pm 16$ \\
\hline LAP (mmHg) & $9 \pm 2.1$ & $19 \pm 9$ \\
\hline \multicolumn{3}{|l|}{ CO $3000 \mathrm{ml}$} \\
\hline Art pressure $(\mathrm{mmHg})$ & $88 \pm 5.6$ & $86 \pm 7.6$ \\
\hline LVP (mmHg) & $93 \pm 7.5$ & $91 \pm 2.3$ \\
\hline DP/DT (mmHg/ms) & $2358 \pm 313$ & $1430 \pm 468$ \\
\hline LVEDP (mmHg) & $11.9 \pm 3.2$ & $23 \pm 5.3$ \\
\hline LAP (mmHg) & $11 \pm 2.6$ & $20 \pm 6.8$ \\
\hline
\end{tabular}

diverted into the pulmonary circulation via the conduit [11]. This model might have clinical or experimental value in the pediatric population and allows studying the role and importance of the right ventricle. Our right heart bypass model has been used to study the efficacy of HBOC-201 as a priming solution in cardiopulmonary bypass $[12,13]$. Using this model, Frank-Starling Curves can be generated in an experimental model and may serve as a cornerstone to study the ventricle function.

Mabuchi et al. [15] studied the right heart bypass model in an animal model by clamping the pulmonary artery. The pulmonary circulation was thereby supplied entirely by the artificial heart and the systemic circulation by the natural heart. This model enabled studies of long-term effects of an artificial right heart on systemic circulation [15].

Our model would allow studying the impact of ischemia after cross clamping in cardiopulmonary bypass. It is already a known principle that global ischemia diminishes LV and RV function [14]. Kitano et al. [16] evaluated the postischemic right ventricular function during left heart bypass using volumetric analysis with a conductance catheter in canines. Using the conductance catheter, the volumetric status of the right ventricle was assessed. Right ventricular pressure-volume curves were created in the presence of a left heart bypass and compared with measured parameters in the absence of the left heart bypass. The study was performed to evaluate the impact of the decompression of the left ventricle and correcting the septal shift (Bernheim effect) during a left heart bypass. A correction of the Bernheim effect would provide a better diastolic compliance and systolic performance because of unloading of unproportional afterload of the right ventricle. The authors concluded that a left heart bypass improved the overall right ventricular performance, particularly at higher end-diastolic pressures in canines with post-ischemic cardiac dysfunction [16].

Isolation of one or the other ventricle allows for accurate study of the opposite ventricle as well as the impact of various agents on myocardial contractility. It also allows for studying the ability of the left ventricle to deal with volume challenge without major changes in intracardiac pressure.

\section{CONCLUSION}

This model can serve as an experimental model to evaluate the left ventricular function and detect the ability of the left ventricle to deal with volume challenge. It allows for a direct measurement of myocardial function and the impact of various inotropic agents on myocardial function. Furthermore, hemodynamic change of hemodynamic and intracardiac pressure changes can be used to create pressure volume curves.

\section{REFERENCES}

[1] Sytkowski PA, Kannel WB, D'Agostino RB. Changes in risk factors and the decline in mortality from cardiovascular disease. The Framingham Heart Study. N Engl J Med 1990; 322(23): 163541 .

[2] Mather PJ, Konstam MA. Newer mechanical devices in the management of acute heart failure. Heart Fail Rev 2007; 12(2): 167-72.

[3] Konstam MA. Progress in heart failure Management? Lessons from the real world. Circulation 2000; 102(10): 1076-8.

[4] Khand A, Gemmel I, Clark AL, et al. Is the prognosis of heart failure improving? J Am Coll Cardiol 2000; 36(7): 2284-6.

[5] Jessup M, Brozena S. Heart failure. N Engl J Med 2003; 348(20): 2007-18.

[6] Ghali JK, Cooper R, Ford E. Trends in hospitalization rates for heart failure in the United States, 1973-1986. Evidence for increasing population prevalence. Arch Intern Med 1990; 150(4): 769-73. 
[7] Tamesue K, Nawa S, Ichiba S, et al. Hemodynamic effects of pumpless extracorporeal membrane oxygenation (ECMO) support for chronically pressure-overloaded right heart failure in a canine experimental model. Surg Today 2005; 35(10): 861-8.

[8] Melchior R, Darling E, Terry B, et al. A novel method of measuring cardiac output in infants following extracorporeal procedures: preliminary validation in a swine model. Perfusion 2005; 20(6): 323-7.

[9] Reitan O, Steen S, Ohlin H. Left ventricular heart failure model for testing cardiac assist devices. ASAIO J 2002; 48(1): 71-5.

[10] Breen PH, Isserles SA. Right atrial bypass model in the dog. Am J Vet Res 1995; 56(2): 208-14

[11] Nawa S, Irie H, Takata $\mathrm{K}$, et al. Development of a new experimental model for total exclusion of the right heart without the aid of cardiopulmonary bypass. J Thorac Cardiovasc Surg 1989; 97(1): 130-4.

[12] Neragi-Miandoab S, Guerrero JL, Vlahakes GJ. Autologous blood sequestration using a double venous reservoir bypass circuit and polymerized hemoglobin prime. ASAIO J 2002; 48(4): 407-11.
[13] Neragi-Miandoab S, Vlahakes GJ. Elevated troponin I level with hemoglobin based oxygen carrying solutions (HBOCs) as a priming solution despite improved left ventricular function. Interact Cardiovasc Thorac Surg 2006; 5(2): 135-8.

[14] Shuman TA, Palazzo RS, Jaquiss RB, et al. A model of right ventricular failure after global myocardial ischemia and mechanical left ventricular support. ASAIO Trans Am Soc Artif Int Organs 1991; 37(3): M212-3.

[15] Mabuchi K, Imachi K, Chinzei T, et al. Use of a total right heart bypass model for analyses of abnormal hemodynamics in total artificial heart animals, and the function and regulatory mechanisms of a natural heart. ASAIO Trans Am Soc Artif Int Organs 1989; 35(3): 705-8.

[16] Kitano M, Nishimura K, Hee PC, et al. Right ventricular function evaluated by volumetric analysis during left heart bypass in a canine model of postischemic cardiac dysfunction. J Thorac Cardiovasc Surg 1995; 109(4): 796-803.

(c) Miandoab and Valahakes; Licensee Bentham Open.

This is an open access article licensed under the terms of the Creative Commons Attribution Non-Commercial License (http://creativecommons.org/licenses/by$\mathrm{nc} / 3.0 /$ ) which permits unrestricted, non-commercial use, distribution and reproduction in any medium, provided the work is properly cited. 